\title{
Lloyd J. Old - a scientific concertmaster
}

n November 28, 2011, Lloyd J. Old succumbed to the disease to which he had contributed so much insight over the course of his illustrious career. On March 19, 2012, many of those whose lives he impacted filled the Rockefeller Research Laboratories Auditorium at Memorial Sloan-Kettering Cancer Center, where he spent his entire professional career, to celebrate his life. The crowd that gathered, their remarks, and the "LJO" stories that they shared reflected his lifelong devotion to his family, cancer immunology, and music, as well as his broad sphere of influence. The selected snapshots shown on a screen as people gathered caught the essence of his life and hinted at the complexity of the man that he was. Old's scientific discoveries have been recounted many times - during his life as his achievements garnered numerous awards and honors, and in the many tributes that have appeared since his death. Yet beyond the broad scope of his contributions, there is much to be said about his unique achievements as a leader of his scientific discipline and of the institutions on which he left his mark.

The fundamental questions that drove Lloyd's research were whether patients mount an immune response to their tumors, and if so what are the tumor antigens, and whether we can harness the immune response by stimulating antitumor immunity to treat cancer. Over the course of his career and lifetime, and in no small part due to his own laboratory's contributions, the potential of the immune system to respond to tumors has been established. Gratifyingly, although not yet a standard of care, proof-of-principle immunebased therapies are emerging, and a limited number of immunotherapies have recently achieved FDA approval.

Lloyd's vision of advancing the field of cancer immunology in particular, and promoting progress in understanding and treating cancer in general, extended far beyond his own laboratory. His approach to conquering the challenges of cancer was to attract bright young scientific talent to the field, support them, provide mechanisms for fostering collaborative efforts, always demand excellence, and tackle scientific questions from all angles including basic research in model systems, without ever losing sight of the reality that these efforts must ultimately translate into benefit to patients. Lloyd faithfully adhered to these principles in his own lab and applied them more broadly when he served as Direc-

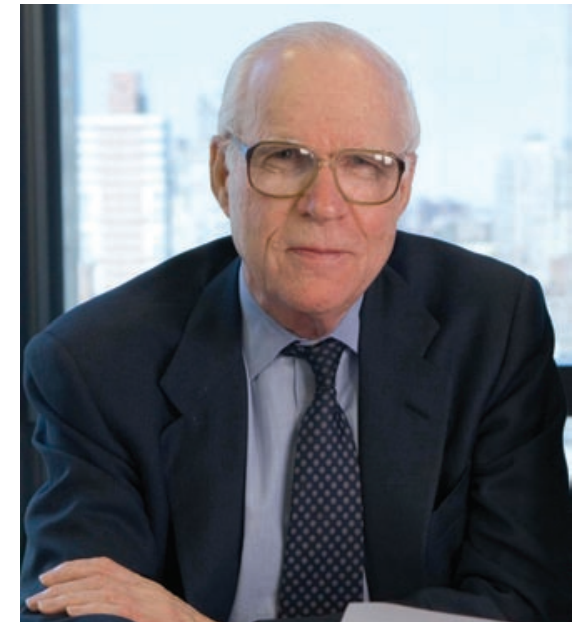

institution, to be awarded every three years.

Lloyd left an equally indelible mark on the LICR, where he provided a vision for a research institute founded on an unprecedented organizational structure with, at its most expansive phase, ten branches in seven countries and a network of affiliates that spanned the globe. Lloyd's propensity to engage in intense discussion on a wide range of topics with other scientists was fundamental to his success. Equally important, however, was his uncanny ability to engage and excite non-scientists about the potential impact of scientific research on the future of cancer treatment and to garner philanthropic support from those he engaged.

Lloyd was a private person, and I would venture to claim that very few - if any - had the chance to know all of his intricately carved facets. But behind his reserved demeanor, Lloyd was a passionate and very caring man. In apparent contradiction to the creativity that characterized his scientific research, he was a man of habit when it came to his daily routine and mundane tasks. But first and foremost, he was a scholar.

Lloyd chose a career in medical research instead of music; had he not, the field of cancer immunology would have charted a very different path. He never appeared to regret his choice, but true to his musical beginnings, in science he often took on the role of the first violinist as concertmaster.

Lloyd loved Mozart and other of the bestknown composers whose work, like his own, have stood the test of time. In recent years, however, Lloyd studied the works of lesserknown classical composers. Given time, I expect he would have enriched the lives of those of us who shared his passion by helping us appreciate the works of lesser-known composers, just as he had a knack for bringing attention to the important findings of less-renowned and younger investigators.

Lloyd continued his research and served our community to the very end. Those of us who worked with him can only hope to honor him by standing by our principles, pursuing our scientific visions, valuing scholarship as he did, and doing our part to maintain and build on the platforms he built to support the field of cancer immunology. this program, the CRI has established two permanently endowed Lloyd J. Old Memorial Fellowships in Cancer Immunology, one of which will permanently reside at Memorial Sloan-Kettering, while the other will be selected independent of the applicant's host

\section{Ellen Puré}

The Wistar Institute, Philadelphia, Pennsylvania, USA. Phone: 215.898.1570; Fax: 215.898.3937; E-mail: pure@wistar.org. 